\title{
Recombination and dynamics of transposable elements in natural populations. A drosophilist's view
}

\author{
I. A. Kozeretska \\ Taras Shevchenko National University of Kyiv \\ 64, Volodymyrska Str., Kyiv, Ukraine, 01601 \\ iryna.kozeretska@gmail.com
}

The concept of the tight link between crossing over and the dynamics of transposable elements is presented. The
behavior of transposable elements influences the processes of homologous recombination, both at the moment of
activation and as a result the changes in a genome caused by active transposition of the autonomous nucleotide
sequences.

Keywords: crossing over, transposable elements, drosophila.

Recombination and mobility of some nucleotide sequences. Homologous recombination (crossing over) was described by Thomas Morgan at the beginning of the last century [1]. This discovery triggered the onset of studies on a phenomenon, a role of which is not absolutely clear even today due to its multifarious effects on biological processes in a single cell in particular, and in organism populations in a whole. Transposable elements (TEs) were independently discovered by two research groups in the late 1970s $[2,3]$. The understanding of TEs has evolved from considering them as parasitic elements to regarding as the evolution drivers [4].

Crossing over (homologous recombination) means the process of exchanging homologous regions between homologous chromosomes. This process occurs in the prophase of the first meiotic division during the $4^{\text {th }}$ chromatids stage or can happen during mitosis. Therefore, the sister chromatids of both homologous chromosomes are involved in crossing over. Successful completion of meiosis in drosophila requires the formation of bivalents, i. e. pair-wise conjugation of homologous chromosomes with further formation of the

(C) Institute of Molecular Biology and Genetics, NAS of Ukraine, 2011 synaptonemal complex. Drosophila melanogaster males lack the synaptonemal complex, and genetic recombination does not usually occur [5], though it still can take place in dysgenic males [6]. In males, the normal pairing and segregation of chromosomes are controlled by two genes active during meiosis, which encode the SNM (stromalin in meiosis) and MNM (Mod in meiosis) proteins [7]. Additionally, the double-strand chromosomal brakes, initiated by the recombination protein MEI-W68 (a type II topoisomerase) [8] with the further invasion of one strand into the sister chromosome and DNA reparation of the ensuing damage, have been shown to constitute an equally necessary condition for homologous recombination to occur [9]. Meanwhile, a synapsis between homologous chromosomes may occur without further homologous recombination in drosophila [10], as well as double-strand brakes may appear even without the synaptonemal complex proteins [11]. Overall, more than 30 genes involved in homologous recombination have been described in drosophila [12].

Chromosomal aberrations (inversions, deletions, translocations) are known to hinder crossing over [13]. This means that crossing over is obstructed between 
chromosome regions with lower homology. Therefore, the recombination frequency within any chosen region of chromosome can serve as an indirect evidence of reduced homology resulting from a number of common reasons, chromosome rearrangements in particular. It is valid to assume that with no chromosome rearrangements in a given region, the crossing over frequency should not differ significantly from that expected on the basis of the genetic map; alternatively, a significantly lower frequency usually suggests lowered homology (including that due to chromosome rearrangements).

In a number of papers the recombination frequency in drosophila has been shown to differ depending on the region of chromosome [14-16]. How is the recombination frequency of a given region of chromosome determined? Usually it is achieved by the juxtaposing of the genetic and cytological maps. The better length agreement of the homologous region between the maps suggests a higher recombination rate [16]. However, the dimensions of the genetic map are greatly affected by the number of genes (markers) in a given region, and this suggests higher recombination rates for regions with higher gene densities. This could explain the lower recombination frequencies determined for telomeric and centromeric regions, as heterochromatin contains much fewer coding sequencing compared to euchromatin [17]. However, the lower recombination rates in centromeric regions may also be caused by heterochromatization or RNA interference, as has been shown for Schizosaccharomyces pombe [18]. This paper shows that crossing over repression in centromeric regions in yeasts is largely controlled by a single geneClr4-Ricl (codes for H3-histone-9-lysine methyltransferase), while gene expression in these regions is controlled by several genes. The presence of special mechanisms of repression may indicate that stability of some sequences in centromeric regions is selected by the evolutionary process.

An interesting pattern appears if chromosome segments with different recombination rates are compared in regard to the following parameters: the content of coding sequences, introns, and intergenic sequences, the number of genes per segment, coding sequences per gene, and intron sequences per gene. It turns out that the segments with high recombination rates are almost invariable regarding the above-mentioned characteris- tics, the segments with low recombination rates are variable, but to a lesser degree than the regions where recombination is absent [14]. This means that regardless of the chromosome region chosen to study crossing over, the most important parameter is the recombination rate of this region. Considering a relative simplicity of working with the $\mathrm{X}$ chromosome [13], its choice appears natural.

Ectopic recombination (nonallelic homologous recombination (NAHR)). Transposable elements are nucleotide sequences capable of independent transposition in a genome [19]. Mobile genetic elements have been shown to be able to generate chromosome rearrangements. Early researchers noted that the genome contained factors causing chromosome rearrangements [20] and the frequency of these events differed among populations [21]. Later, the presence of TEs in close vicinity of the brake points of some cosmopolitan inversions was demonstrated in D. melanogaster [22] and $D$. buzatti [23]. A possibility of TE-linked chromosome rearrangements was shown in drosophila under experimental conditions [24]. Their initiation is attributed to the phenomenon called ectopic recombination. «Ectopic» literally means «not in place». Although chromosome pairing, which requires substantial homology, must precede recombination in drosophila, synapsis, as mentioned above, is possible without it. Perhaps, it is this feature (the possibility of synapsis without strong homology) that provides for ectopic recombination in this group, unlike in yeasts and some plants [25]. Such recombination strategy in drosophila is believed to represent a defensive mechanism against unbalanced recombination, which, although rare, still takes place and might have been much more frequent inasmuch as the genomes of multicellular organisms contain repetitive sequences [10]. Near 6,000 mobile elements are known so far which belong to over 150 families in $D$. melanogaster. Given that genomes usually contain several identical copies of mobile elements [26], chromosomal DNA molecules are expected to contain several homologous sequences of particular TEs. These repeats should be causative of recombination both within and between chromosomes. Moreover, it is this recombination that is thought to constitute one of the mechanisms which defend genomes against excessive proliferation of TEs [27, 28]. It has been argued that ectopic, as well 
as homologous, recombination can occur during both meiosis and mitosis, which suggests that the mechanisms in question may be inherent in both generative and somatic cells. According to this hypothesis, ectopic recombination decreases the number of TEs in the genome. Some authors, however, have a different opinion which attributes the TE number decrease to selection that acts against insertions (the Hill-Robertson effect) $[27,28]$. The most probable scenario may well incorporate both mechanisms, and it even may prove plausible to anticipate the domination of the Hill-Robertson effect in regions with high gene densities versus that of ectopic recombination in regions with low densities of coding sequences. Another opinion is based on insertion neutrality [27,28], but this one seems not to be linked to recombination processes.

The existence of yet another mechanism related to TE regulation by piRNAs (piwiinteracting RNAs) [29] and endo-siRNA (endogenous small interfering RNAs) [30] is beyond doubt today, but it does not exclude the possibility of the three aforementioned mechanisms of regulation of TE numbers. This mechanism is not directly linked to crossing over, but still contributes to heterochromatin formation [31] and, thus, may indirectly affect recombination as well.

As mentioned above, crossing over requires substantial sequence homology. Ectopic recombination, on the other hand, requires lower levels of homology, and is site specific. The question of how exactly homologous sequences recognize each other is still open, although homolog association, which takes place well before cell division, is believed to be a necessary prerequisite of homologous chromosome pairing [24]. As has already been mentioned, double-strand brakes in the DNA molecule are necessary for successful homologous recombination [9]. $P$ mobile element excision (perhaps it is true for all the other transposons which transpose via the «cut and paste» mechanism) is accompanied by a double-strand brake which is repaired by the homologous recombination reparation enzymes [32]. Double-strand DNA breaks lead to the invasion of a single-strand DNA region, which in D. melanogaster is controlled by the protein DmRad51. The latter is encoded by the gene spn-A9, it facilitates the formation of a nucleoprotein filament at the 3 ' end of the doublestrand brake, and catalyzes the ATP-dependent inva- sion of the single-strand branch $[32,33]$. Hereby, the transposon-mediated double-strand brakes in the DNA molecule may well be agents that increase recombination rates in the regions where such brakes are formed.

The whole body of evidence mentioned above is in agreement with the observation that ectopic recombination often takes place in regions where crossing over is common, and, inversely, it is impeded in regions where crossing over does not occur at all. The putative link between ectopic recombination and crossing over reveals itself through the fact that telomeric and centromeric regions of chromosomes, where crossing over does not occur, contain much more TEs compared to euchromatin [14], and negative correlation exists between the homologous recombination rates and the number of TEs in a given chromosome region $[14,34]$. The assumption that it is the recombination frequency inherent in a given chromosome region that determines the number of TEs in this region is supported by the fact that TEs are more frequent within inversions compared to the same chromosome regions that lack chromosome rearrangements $[35,36]$. However, it should be admitted that these patterns are universal neither to all TEs nor to all chromosome regions [16].

Still another feature of ectopic recombination deserves consideration. This type of recombination has been shown to occur much more often in heterozygotes compared to homozygotes [24]. This is expected given that the homologous recombination repair enzymes need a matrix to base the reparative DNA synthesis on [37], so that in case an excised transposon is present only in one of the homologous chromosomes, the probability of ectopic recombination increases, as the matrix can be found elsewhere, perhaps in another region of the chromosome or even on some other chromosome. Therefore, on the one hand ectopic recombination requires the conditions prerequisite to crossing over; on the other hand, however, it is stimulated by some homology derangements. From this perspective, natural populations are expected to demonstrate much higher rates of ectopic recombination compared to lab lineages.

An indirect evidence suggesting that ectopic recombination occurs only where crossing over takes place may be implied from the studies demonstrating much higher numbers of TEs in two separate drosophila cells cultures compared to the whole organism genomes 
[38]. An increase in the number of copies of the mobile element 1731 has been shown to result from its activity [39]. The authors attribute this to an increase in TE activity in response to a stress experienced by the cells put into culture. But another explanation is possible the absence of meiotic recombination. Sexually reproducing organisms undergo meiosis every generation, thus giving room for ectopic recombination which limits the number of TEs. Homologous recombination does occur in mitotic cells. However, mitotic crossing over is largely restrained to sister chromatids as a result of the activity of ORD protein (encoded by the gene orientation disrupter, ord) $[25,28]$. This process limits the number of TEs in the genomes of cultured cells to a much smaller amount.

Crossing over, TEs, and variability. Recombination is known to stop between a group of genes that are a part of any given inversion; so variability, that would otherwise result from crossing over in the given chromosome region, is reduced. Formerly it was believed that such inversions had adaptive significance, as they fixed a certain set of alleles in a population. This assumption was based on the existence of cosmopolitan inversions, i. e. certain types of rearrangements that are wide-spread in fruit fly populations. Recent studies demonstrate that these rearrangements do not have adaptive value ([40] cited after [41]). However, it should be indicated that specifically the regions, where crossing over does not occur, accumulate many TEs [36] - an expected phenomenon providing that blocking of homologous recombination precludes ectopic recombination as well. On the other hand, TE aggregation increases variability within the inversion region. A balance of variability in certain regions of chromosomes is, therefore, achieved in this way.

Based on early experimental studies using in situ hybridization, it has been postulated in the literature that TE insertions have no effect on the frequency of homologous recombination in the region concerned [42]. Meanwhile, $1 \%$ recombination has been shown to correspond to over $280 \mathrm{~kb}$ of DNA in the right arm of chromosome 3 in D. melanogaster depending on the region [9]. Considering that there are genetic distances proportional to $0.1 \%$ [43], the lengths become commensurate to TE lengths, which are known not to exceed $10 \mathrm{~kb}$. This suggests that the question of the impact of TEs on homologous recombination in certain regions of chromosomes requires further research. Besides, TEs are known to form so-called «nests», where one or more elements are found inside another one [44]. The size of such a nest can exceed the maximal size of full-length members of respective TE families and approach the lengths at which they begin to share the game of homologous recombination. For the ca. 6000 TEs known from Drosophila genome, 500 such nests have been found to occur in all chromosomes, although distributed more densely in the regions where TE densities are higher [45].

It should be noted, however, that the degree of homology derangement, that is needed to affect the frequency of crossing over, is presently unknown. Besides, specific sites are believed to exist in nucleotide sequences upon which the complexes are assembled (socalled early and late recombination nodules) that later promote both pairing of homologous chromosomes and double-strand brake generation. In drosophila, these late nodules are thought to form on the chromosome regions where later proteins of synaptonemic complex are gathered $[28,45]$. Inasmuch as recognition of a sequence (or structure of DNA regions compacted in a particular way) by synaptonemic complex proteins or their relatives is anticipated here, it is clear that such sequences can hardly be represented by TEs, which are sometimes called genomic «parasites» to underline that they are distinct and extrinsic to the host genome DNA proper. Thus, the sequences of TEs that have not become domesticated [46] are not involved in such interactions, which eventually does not affect recombination rates at their insertion site.

Although the spread of TE sequences among different drosophila species has a long history of study [47-49], it still remains topical. In the study of copia, $m d g 1$ and 412 elements in D. melanogaster and D. simulans Biemont et al. has not shown any negative correlation between recombination rates and TE numbers in a set of chromosome regions [49]. Bartolome et al. have found a significant negative correlation between recombination rates and TE densities in some regions in the $2 \mathrm{R}, \mathrm{X}, 4^{\text {th }}$ chromosomes in D. melanogaster [14]. In a study on the dispersal of 54 different TE families in chromosomes of $D$. melanogaster, Rizzon et al. have demonstrated higher densities but no negative correla- 
tion for LTR and non-LTR retrotransposons (elements that translocate via RNA intermediates), and, at the same time, a negative correlation with recombination rates for «cut-and-paste» transposons [15]. The authors have demonstrated that TE densities are much higher in the centromeric regions of chromosomes compared to the central parts of their arms, and yet are comparable to the central parts in telomeric regions. The review of the second release of $D$. melanogaster genome revealed higher TE frequencies in both telomeric and centromeric chromosome regions. In general, euchromatin was shown to contain over 1500 TEs [50], but in the fourth release, the number of recovered TE reached over 6 thousand [25]. The pooled body of all known TEs now showed higher TE frequencies in the centromeric regions compared to telomeric, but these counts differ between the TE classes [44]. However, it must be emphasized that the current data are still not final, as new approaches in TE identification increase the estimated numbers of TE copies in D. melanogaster genome [51]. Therefore, definitive patterns of ME dispersal over chromosomes are supposed not to appear before all sequences that change their positions and the number of copies are determined. It is worth mentioning separately that the number of TEs in any given chromosome region is not constant.

As mentioned earlier, genomes limit multiplication of TEs by means of ectopic recombination and selection against insertions. It was believed formerly that there must be a balance between TE insertions into new regions and their excision from the site they occupy. And these processes must be family-specific [27]. However, inasmuch as at least two elements $-P$ and hoboare known in $D$. melanogaster whose invasion has occurred during the last century in some populations and is still going on in others, this balance seems not to exist, and genomes undergo dynamic changes that still need to be studied [52].

Chromosomal characteristics of recombination and TE insertional patterns. The karyotype of the species $D$. melanogaster is represented by 4 pairs of chromosomes: the $\mathrm{X}$ and $\mathrm{Y}$ sex chromosomes and three pairs of autosomes [13]. As described earlier, higher TE frequencies in pericentromeric heterochromatin compared to other parts of chromosomes are common to all the chromosomes [16]. Some authors note higher TE con- tents in the telomeric chromosome regions as well [14], but recent studies demonstrate that this pattern is not typical of most of ME families [53]. As already stated, the uneven TE distribution is linked to the difference in recombination rates in any given chromosome region. As these rates differ not only within specific regions [14], but among chromosomes as well, it becomes clear that there must be some chromosome-specific issues, which are going to be briefly addressed below.

For the majority of elements (not for all though, as natural populations are heterogeneous with regards to the patterns and presence of specific families), their frequencies have been shown to be significantly lower in the $\mathrm{X}$ chromosome compared to the autosomes, regardless of the similarity in the recombination rates. This can be explained by the iterative hemizygotic stage the $\mathrm{X}$ chromosomes undergo in every generation of males, which leads to the elimination of many insertions that would be preserved in a heterozygotic state [16].

The fourth pair, so-called microchromosomes, has lower recombination rates and much higher TE frequencies compared to other autosomes [54]. However, according to the data obtained by Bartolome et al., the number of TEs per region with a zero recombination rate is greater in the right arm of the $2^{\text {nd }}$ chromosome compared to the sex $(\mathrm{X})$ chromosome, and that in the latter is, in turn, greater compared to the $4^{\text {th }}$ chromosome [14]. Retrospective population studies indicate that fixation of some insertion in the case of the $4^{\text {th }}$ chromosome, and this allows the authors to conclude that this chromosome is currently on its early stages of degeneration [55]. Microchromosomes are so different with regard to recombination and TE insertions that the $4^{\text {th }}$ chromosome is often analyzed separately from the others [32]. Various correlations with recombination rates have been defined for different TEs that are present in the $2^{\text {nd }}$ and $3^{\text {rd }}$ autosomes [55].

Nonetheless, the conclusive body of evidence indicates that a globally negative correlation between the TE frequencies and recombination rates is characteristic of the left arms of the $2^{\text {nd }}$ and $3^{\text {rd }}$ chromosomes and the right arm of the $2^{\text {nd }}$ one. Such a pattern has not been observed in the right arm of the $3^{\text {rd }}$ chromosome, which is interpreted as a result of its putatively peculiar structure, different from that of the $2^{\text {nd }}$ chromosome and the right arm of the $3^{\text {rd }}$ one [16]. 
All the material discussed heretofore allows for, with certain limitations, the prediction of the following link between the described phenomena: TE activation results in their active transposition, which generates new sites of their location in chromosomes in heterozygous state and, thus, promotes chromosomal aberrations, which, in turn, lower the frequency of crossing over in the region in question. Later, the accumulation of new TE insertions takes place in these regions, and these newly integrated TEs, under TE activating conditions, may trigger this chain of events further.

The studies of the $2^{\text {nd }}, 3^{\text {rd }}$, and X chromosomes in natural populations of D. melanogaster from Moldova have revealed lower or equal to the theoretically expected recombination rates inferred from the genetic map. The authors interpret these rates as resulting from rearrangements in the studied chromosome regions; although chromosome structure itself was not studied [56]. Eight natural fruit fly populations from Ukraine studied during 2005-2007 in a region of the X chromosome have shown lower recombination frequencies compared to the expected based on the genetic map [57], which is in agreement with the results obtained by the authors cited above.

Meanwhile, Moldova natural fruit fly populations studied by Vereshchagina et al. in 2008 and 2009 [56] have shown cases in which the frequency of homologous recombination was higher than theoretically expected. As mentioned earlier, double-strand brakes are prerequisite to crossing over [8]. Transposons, one of the two TE classes, are known to form, while transposing, doublestrand gaps in the sites they are excised from. As the factors causing these derangements in DNA molecules (e. g. radiation [58]) promote crossing over, it can be predicted that active transposition by the elements of this TE class may thus cause increased frequency of homologous recombination in the regions where TEs are active.

Therefore, based on the data presented here, a tight link can be postulated between homologous recombination and TE transposition in the D. melanogaster genome, the former being theoretically suitable as an indirect marker of the activity of the «genome evolution drivers» in natural populations of this species. Considering the methodology it should be stressed that, although perhaps not for all cases, the sex chromosome pair is the best choice for the analysis of this kind.
Acknowledgements. The present work was performed within the framework of Fulbright scholar program 2010, and has become possible using the facilities of Thomas Cooper Library of the University of South Carolina (USA) and thanks to the invaluable help by Prof. Timothy Mousseau.

\section{I. А. Козерецька}

Рекомбінація і динаміка мобільних генетичних елементів у природних популяціях. Бачення дрозофіліста

\section{Резюме}

Викладено уявлення про те, що процеси кросинговеру та динаміки мобільних генетичних елементів перебувають у тісному взаємозв'язку. Поведінка мобільних елементів геному впливає на прочеси гомологічної рекомбінації як безпосередньо в момент активації, так $і$ внаслідок змін, що відбуваються в геномах $у$ результаті активного переміщення автономних нуклеотидних послідовностей.

Ключові слова: рекомбінація, мобільні генетичні елементи, дрозофіла

\section{И. А. Козеречкая}

Рекомбинация и динамика мобильных генетических элементов в природных популяциях. Взгляд дрозофилиста

Резюме

Изложено представление о том, что процессы кроссинговера и динамики мобильных генетических элементов находятся в тесной взаимосвязи. Поведение мобильных элементов генома влияет на процессы гомологичной рекомбинации как непосредственно в момент активации, так и вследствие изменений, происходящих в геномах в результате активного перемещения автономных нуклеотидных последовательностей.

Ключевые слова: рекомбиначия, мобильные генетические элементы, дрозофила.

\section{REFERENCES}

1. Morgan T. H. Chromosomes and associative inheritance // Science.-1911.-34, N 880.-P. 636-638.

2. Ilyin Yu. V., Tchurikov N. A., Ananiev E. V., Ryskov A. P., Yenikopolov G. N., Limborska S. A., Maleeva N. E., Gvozdev V. A., Georgiev G. P. Studies on the DNA fragments of mammals and Drosophila containing structural genes and adjacent sequences // Cold Spring Harb. Symp. Quant Biol.-1978.-42, Pt 2.P. 959-969.

3. Finnegan D. J., Rubin G. M., Young M. W., Hogness D. S. Repeated gene families in Drosophila melanogaster // Cold Spring Harb. Symp. Quant Biol.-1978.-42, Pt 2.-P. 1053-1063.

4. Kazazian H. H. Jr. Mobile elements: drivers of genome evolution // Science.-2004.-303, N 5664.-P. 1626-1632.

5. Morgan T. H. No crossing over in the male of drosophila of genes in the second and third pairs of chromosomes // Biol. Bull.-1914.-26, N 4.-P. 195-204.

6. Kidwell M. G. Evolution of hybrid dysgenesis determinants in Drosophila melanogaster // Proc. Natl Acad. Sci. USA.-1983.80, N 6.-P. 1655-1659. 
7. Thomas S. E., McKee B. D. Meiotic pairing and disjunction of mini-X chromosomes in Drosophila is mediated by 240-bp rDNA repeats and the homolog conjunction proteins SNM and MNM // Genetics.-2007.-177, N 2.-P.785-799.

8. McKim K. S., Hayashi-Hagihara A . mei-W68 in Drosophila melanogaster encodes a Spo11 homolog: evidence that the mechanism for initiating meiotic recombination is conserved // Genes Dev.-1998.-12, N 18.-P. 2932-2942.

9. McKim K. S., Jang J. K., Manheim E. A. Meiotic recombination and chromosome segregation in Drosophila female // Annu. Rev. Genet.-2002.-36.-P. 205-232.

10. McKim K. S., Green-Marroquin B. L., Sekelsky J. J., Chin G., Steinberg C., Khodosh R., Hawley R. S. Meiotic synapsis in the absence of recombination // Science.-1998.-279, N 5352.P. 876-878.

11. Jang J. K., Sherizen D. E., Bhagat R., Manheim E. A., McKim K. $S$. Relationship of DNA double-strand breaks to synapsis in Drosophila // J. Cell Sci.-2003.-116, Pt 15.-P. 3069-3077.

12. Anderson J. A., Gilliland W. D., Langley G. H. Molecular population genetics and evolution of Drosophila meiosis genes // Genetics.-2009.-181, N 1.-P. 177-185.

13. Ashburner M., Golic K. G., Hawley R. S. Drosophila: A laboratory handbook.-New York: Cold Spring Harbor Lab. Press, 2004.-P. 481-606.

14. Bartolome C., Maside X., Charlesworth B. On the abundance and distribution of transposable elements in the genome of Drosophila melanogaster // Mol. Biol. Evol.-2002.-19, N 6.P. 926-937.

15. Rizzon C., Marais G., Gouy M., Biemont C. Recombination rate and the distribution of transposable elements in the Drosophila melanogaster genome// Genome Res.-2002.-12, N 3.-P. 400-407.

16. Hoogland C., Biemont C. Chromosomal distribution of transposable elements in Drosophila melanogaster: test of the ectopic recombination model for maintenance of insertion site number // Genetics.-1996.-144, N 1.-P. 197-204.

17. Hughes $S$. E., Hawley $R$. S. Heterohromatin: a rapidly evolving species barrier // PLoS Biol.-2009.-7, N 10.-P. e1000233.

18. Ellermeier C., Higuchi E. C., Phadnis N., Holm L., Geelhood J. L., Thon G., Smith G. R. RNAi and heterochromatin repress centromeric, meiotic recombination // Proc. Natl Acad. Sci. USA.2010.-107, N 19.-P. 8701-8705.

19. Slotkin R. K., Martienssen R. Transposable elements and the epigenetic regulation of the genome // Nat. Rev. Genet.-2007.-8, N 4.-P. 272-285.

20. Ives $P$. T. The importance of mutation rate genes in evolution // Evolution.-1950.-4, N 3.-P. 236-252.

21. Yamaguchi O., Mukai T. Variation of spontaneous occurrence rates of chromosomal aberrations in the second chromosomes of Drosophila melanogaster // Genetics.-1974.-78, N 4.-P. 12091221.

22. Zabalou S., Alahiotis S. N., Yannopoulos G. A three-season comparative analysis of the chromosomal distribution of $P$ and hobo mobile elements in a natural population of Drosophila melanogaster // Hereditas.-1994.-120, N 2.-P. 127-140.

23. Caceres M., Ranz J. M., Barbadilla A., Long M., Ruiz A. Generation of a widespread Drosophila inversion by a transposable elements // Science.-1999.-285, N 5426.-P. 415-418.

24. Montgomery E. A., Huang S. M., Langley C. H., Judd B. H. Chromosome rearrangement by ectopic recombination in Drosophila melanogaster: genome structure and evolution // Genetics.-1991.-129, N 4.-P. 1085-1098.

25. Pawlowski W. P., Cande W. Z. Coordinating the events of the meiotic prophase // Trends Cell Biol.-2005.-15, N 12.-P. 674-681.
26. Quesneville H., Bergman C. M., Andrieu O., Autard D., Nouaud D., Ashburner M., Anxolabehere D. Combined evidence annotation of transposable elements in genome sequences // PLoS Comput. Biol.-2005.-1, N 2.-P. e22.

27. Le Rouzic A., Deceliere G. Models of the population genetics of transposable elements // Genet. Res.-2005.-85, N 3.-P. 171-181.

28. Petrov D. A., Aminetzach Y. T., Davis J. C., Bensasson D., Hirsh $A$. E. Size matters: non-LTR retrotransposable elements and ectopic recombination in Drosophila // Mol. Biol. Evol.-2003.20, N 6.-P. 880-892.

29. Lee Y. C., Langley C. H. Transposable elements in natural populations of Drosophila melanogaster // Philos. Trans. R. Soc. Lond. B. Biol. Sci.-2010.-365, N 1544.- P. 1219-1228.

30. Rozhkov N. V., Aravin A. A., Zelentsova E. S., Schostak N. G., Sachidanandam R., McCombie W. R., Hannon G. J., Evgen'ev M. $B$. Small RNA-based silencing strategies for transposons in the process of invading Drosophila species // RNA.-2010.-16, N 8.-P. 1634-1645

31. Moshkovich N., Lei E. P. HP1 recruitment in the absence of argonaute proteins in Drosophila // PLoS Genet.-2010.-6, N 3.P. e1000880.

32. Engels W. R., Johnson-Schlitz D. M., Eggleston W. B., Sved J. High-frequency $P$ element loss in Drosophila is homolog dependent // Cell.-1990.-62, N 3.-P. 515-525.

33. Staeva-Vieira E, Yoo S, Lehmann R. An essential role of DmRad51/SpnA in DNA repair and meiotic checkpoint control // EMBO J.-2003.-22, N 21.-P. 5863-5874.

34. McVey M., Adams M., Staeva-Vieira E., Sekelsky J. J. Evidence for multiple cycles of strand invasion during repair of doublestrand gaps in Drosophila // Genetics.-2004.-167, N 2.-P. 699705 .

35. Haddrill P. R., Halligan D. L., Tomaras D., Charlesworth B. Reduced efficacy of selection in regions of the Drosophila genome that lack crossing over // Genome Biol.-2007.-8, N 2.-R18.

36. Sniegowski P. D., Charlesworth B. Transposable element numbers in cosmopolitan inversions from a natural population of Drosophila melanogaster // Genetics.-1994.-137, N 3.-P. 815827.

37. Haber J. E. Partners and pathwaysrepairing a double-strand break // Trends Genet.-2000.-16, N 6.-P. 259-264.

38. Potter S. S., Brorein W. J. Jr., Dunsmuir P., Rubin G. M. Transposition of elements of the 412 , copia and 297 dispersed repeated gene families in Drosophila // Cell.-1979.-17, N 2.-P. 415-427.

39. Maisonhaute C., Ogereau D., Hua-Van A., Capy P. Amplification of the 1731 LTR retropransposon in Drosophila melanogaster cultured cells: origin of neocopies and impact on the genome // Gene.-2007.-393, N 1-2.-P. 116-126.

40. Inversion polymorphism in Drosophila / Eds C. B. Krimbas, J. R. Powell.-Boca Raton: CRC Press, 1991.-560 p.

41. Hasson E., Eanes W. F. Contrasting histories of three gene regions associated with In(3L)Payne of Drosophila melanogaster // Genetics.-1996.-144, N 4.-P. 1565-1575.

42. Ananiev E. V., Barsky V. E. Elektronno-mikroskopicheskaia karta politennykh khromosom sliunnykh zhelez drosophily: D. melanogaster.-Moskva: Nauka, 1985.-85 p.

43. Tweedie S., Ashburner M., Falls K., Leyland P., McQuilton P., Marygold S., Millburn G., Osumi-Sutherland D., Schroeder A., Seal R., Zhang H., FlyBase Consortium. FlyBase: enhancing Drosophila gene ontology annotations // Nucl. Acids Res.2009.-37.-D555-D559.

44. Bergman C. M, Quesneville H., Anxolabehere D., Ashburner M. Recurrent insertion and duplication generate networks of transposable element sequences in the Drosophila melanogaster genome // Genome Biol.-2006.-7, N 11.-P. R112. 
45. Sherizen D., Jang J. K., Bhagat R., Kato N., McKim K. S. Meiotic recombination in Drosophila females depends on chromosome continuity between genetically defined boundaries // Genetics.-2005.-169, N 2.-P. 767-781.

46. Quesneville H., Nouaud D., Anxolabehere D. Recurrent recruitment of the THAP DNA-binding domain and molecular domestication of the P-transposable element // Mol. Biol. Evol.2005.-22, N 3.-P. 741-746.

47. Gvozdev V. A., Kaidanov L. Z. Genomic variability caused by transposition of mobile elements and fitness of individuals in Drosophila melanogaster // Zhur. Obshch. Biol.-1986.-47, N 1.-P. 51-63.

48. Golubovsky M. D., Zakharov I. K., Sokolova O. A. Analysis of instability of the yellow gene alleles isolated from natural drosophila populations during the period of mutability outburst // Genetika.-1987.-23, N 9.-P. 1595-1603.

49. Biemont C., Vieira C., Hoogland C., Cizeron G., Loevenbruck C., Arnault C., Carante J. P. Maintenance of treansposable elelemts copy number in natural populations of Drosophila melanogaster and D. simulans // Genetica.-1997.-100, N 1-3.-P. 161166.

50. Kaminker J. S, Bergman C. M, Kronmiller B., Carlson J., Svirskas R., Patel S., Frise E., Wheeler D. A., Lewis S. E., Rubin G. M., Ashburner M., Celniker S. E. The transposable elements of the Drosophila melanogaster euchromatin: a genomics perspective // Genome Biol.-2002.-3, N 12.-0084.1-0084.2.

51. Rho M., Choi J.-H., Kim S., Lynch M., Tang H. De novo identification of LTR retrotransposons in eukaryotic genomes // BMC Genomics.-2007.-8.-P. 90.

52. Le Rouzic A., Deceliere G. Models of the population genetics of transposable elements // Genet. Res.-2005.-85, N 3.-P. 171181.
53. Caspi A., Pachter L. Identification of transposable elements using multiple alignments of related genomes // Genome Res.-2006.16, N 2.-P. 260-270.

54. Bartolome $C$., Maside $X$. The lack of recombination drives the fixation of transposable elements on the fourth chromosome of Drosophila melanogaster // Genet. Res.-2004.-83, N 2.-P. 91100.

55. Smith D., Wohlgemuth J., Calvi B. R., Franklin I., Gelbart W. M. hobo enhancer trapping mutagenesis in Drosophila reveals an insertion specificity different from $P$ elements // Genetics.-1993.135, N 4.-P. 1063-1076.

56. Vereshchagina N. M., Iliadi I. K., Nikitich O. A. Comparative studies of $P$ - and hobo-element activity, fitness components and recombination parameters in two natural populations of Drosophila melanogaster in Moldova // Hereditas.-1994.-120, N 2.P. 91-98.

57. Kozeretska I. A., Procenko O. V., Demidov $S$. $V$. Recombination events in offspring of Drosophila flies collected from natural populations in Ukraine // Problemy Ekologicheskoy i Meditsinskoy Genetiki i Klinicheskoy Immunologii.-2009.-3, N 90.P. 35-43.

58. Feschotte C., Pritham E. J. DNA transposons and the evolution of eukaryotic genomes // Annu. Rev. Genet.-2007.-41.-P. 331368 .

UDC 579.88:591.557.61:595.771 Received 05.11.10 